\title{
Characterizing and identifying structural domains at rifted continental margins: application to the Bay of Biscay margins and its Western Pyrenean fossil remnants
}

J. Tugend, G. Manatschal, N. J. Kusznir \& E. Masini

\section{SUPPLEMENTARY FIGURES}

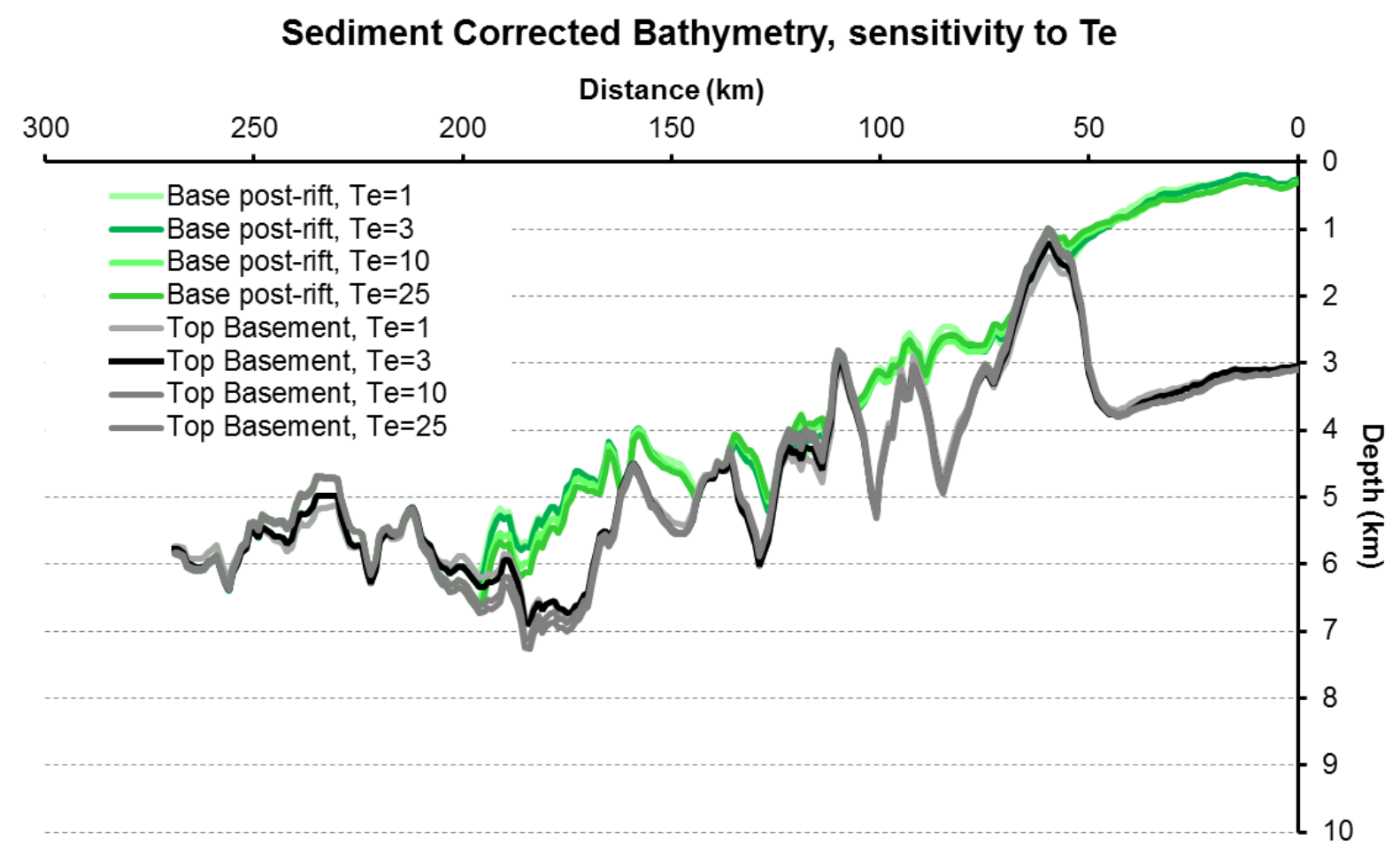

Supplementary Figure S1: Influence of effective elastic thickness (Te) on post-rift sediment corrected bathymetry determined from 2D flexural backstripping. A range of Te values have been tested: $\mathrm{Te}=1 ; \mathrm{Te}=3 ; \mathrm{Te}=10 ; \mathrm{Te}=25$. Note the similarity between the different results. 


\section{Bathymetry at break up, sensitivity to Te}

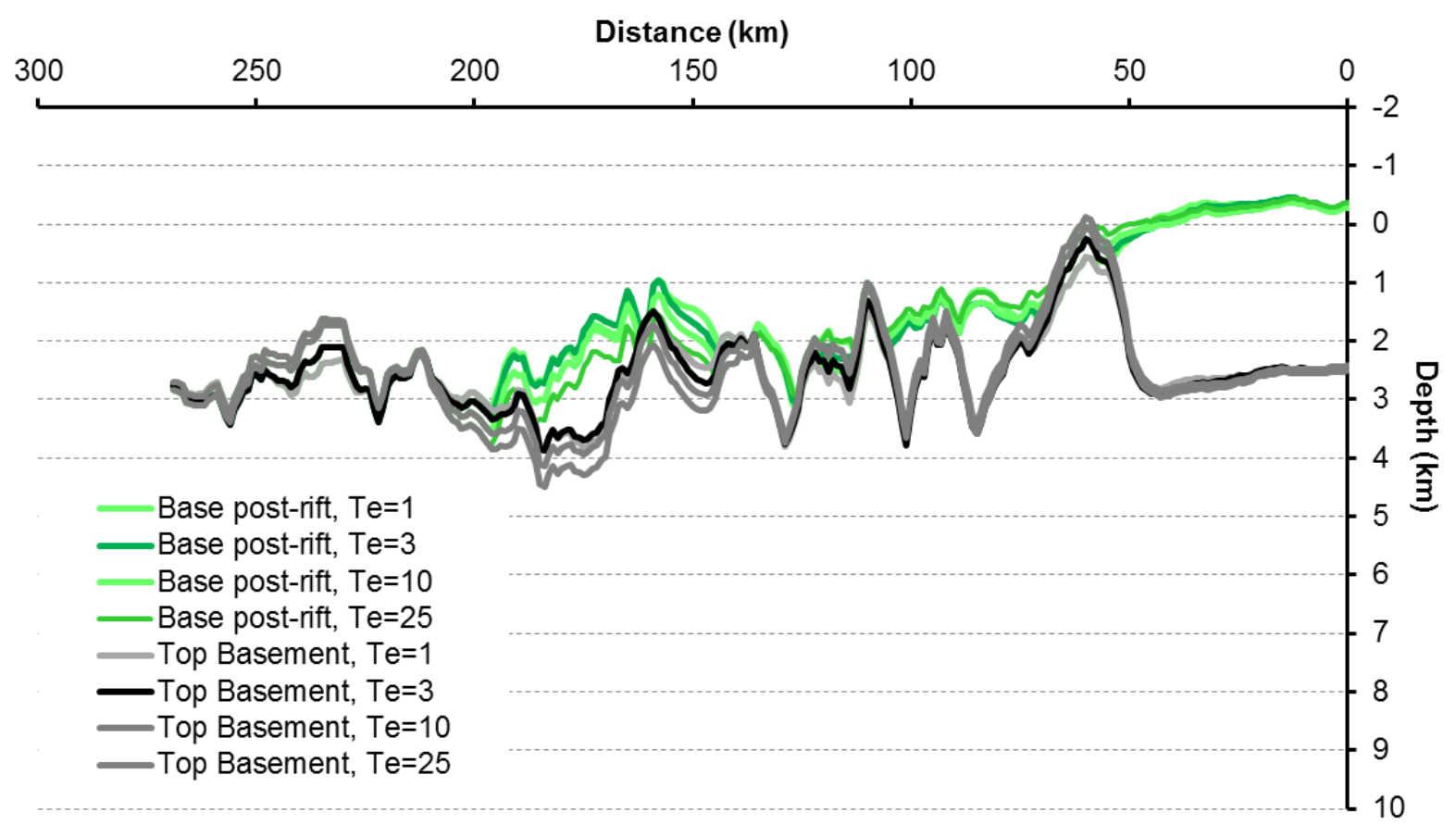

Supplementary Figure S2: Influence of effective elastic thickness (Te) on the bathymetry at break-up predicted from 2D flexural backstripping, including inverse thermal modelling (Kusznir et al. 1995; Roberts et al. 1998). A range of Te values have been tested: $T e=1$; $\mathrm{Te}=3 ; \mathrm{Te}=10 ; \mathrm{Te}=25$. Note the similarity between the different results. 


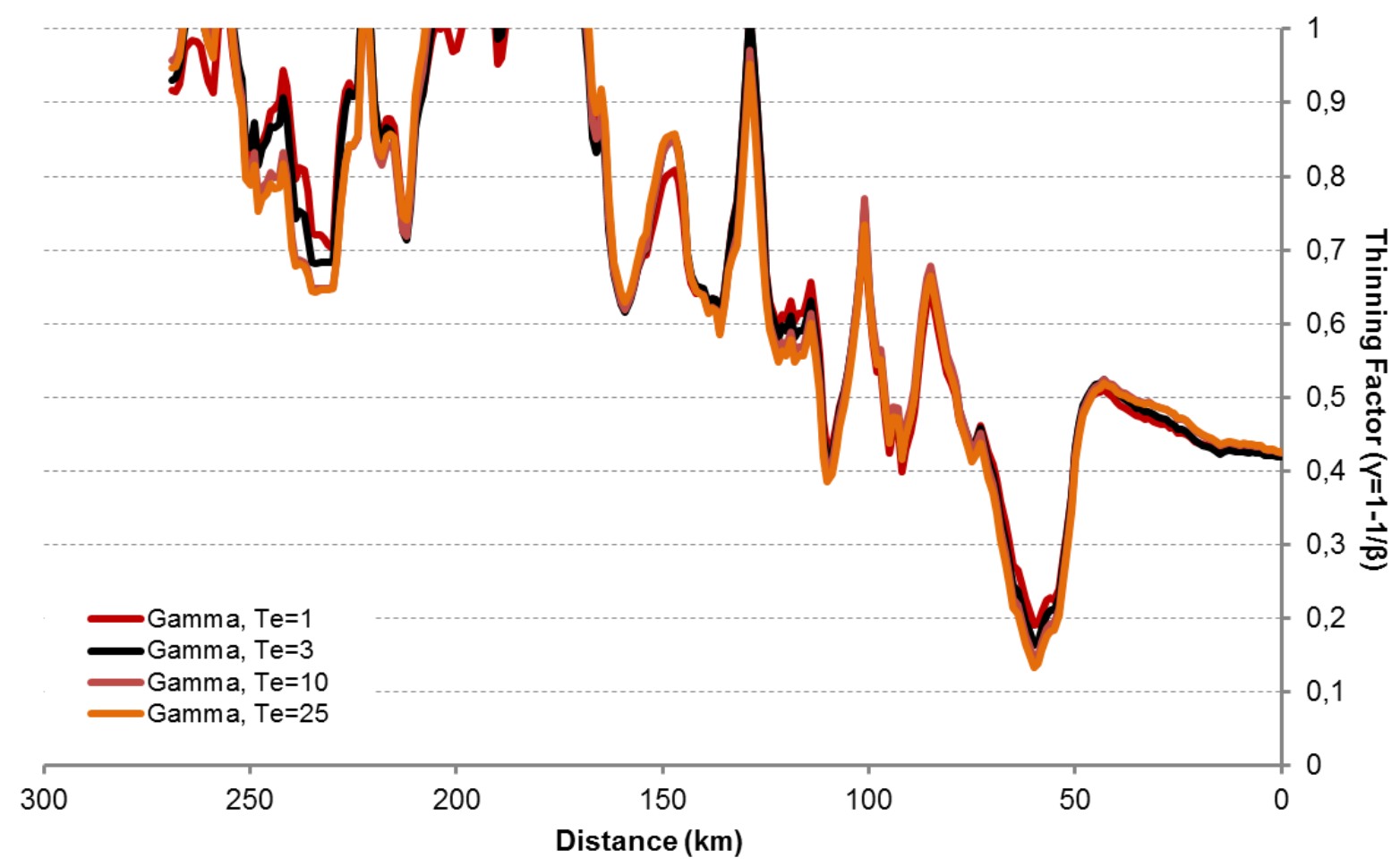

Supplementary Figure S3: Influence of effective elastic thickness (Te) on the lithosphere thinning factor determined from 2D flexural backstripping. A range of Te values have been tested: $\mathrm{Te}=1 ; \mathrm{Te}=3 ; \mathrm{Te}=10 ; \mathrm{Te}=25$. In spite of the different values of $\mathrm{Te}$ tested, results are remarkably similar.

\section{REFERENCES}

KUSZNIR, N. J., ROBERTS, A. M. \& MORLEY, C. K. 1995. Forward and reverse modelling of rift basin formation. In: LAMBIASE, J. (ed.) Hydrocarbon Habitat in Rift Basins. Geological Society, London, Special Publications, 80, 33-56.

ROBERTS, A. M., KUSZNIR, N. J., YIELDING, G. \& STYLES, P. 1998. 2D flexural backstripping of extensional basins; the need for a sideways glance. Petroleum Geoscience, 4, 327-338. 